\title{
"COMPORTAMENTOS ANTISSOCIAIS NA INFÂNCIA E JUVENTUDE EM PORTUGAL (DÉCADAS DE 70 A 90 DO SÉCULO XX): INCURSÕES EXPLORATÓRIAS"
}

\author{
"Antisocial behavior in Childhood and Youth in \\ Portugal (70-90 decades of the twentieth century): \\ exploratory incursions"
}

Helder Henriques*

Carla Vilhena** $^{* *}$

\begin{abstract}
RESUMO
Este texto tem como objeto de análise discursos sobre as crianças e os jovens delinquentes que circularam em Portugal, no período compreendido entre as décadas de 70 e 90 do século XX. Do ponto de vista empírico, tomamos como referência a legislação produzida sobre esta temática, assim como o estudo da revista "Infância e Juventude", propriedade da Federação Nacional das Instituições de Proteção à Infância, no arco temporal previsto. Começaremos por apresentar o quadro histórico de evolução do sistema de justiça de menores em Portugal ao longo de novecentos, para depois analisarmos o processo de construção social da categoria criança e jovem delinquente, fazendo particular referências quer àquelas que eram consideradas as causas deste problema, quer às soluções propostas.
\end{abstract}

Palavras-chave: Risco; Infância e Juventude; Delinquência; História; Marginalidade

* Doutor em Ciências da Educação, com especialização em História da Educação, pela Universidade de Coimbra. Professor da Escola Superior de Educação do Instituto Politécnico de Portalegre (IPP/ESE). Investigador no CEIS20/Universidade de Coimbra. E-mail: henriqueshelder@gmail.com

** Professora Auxiliar na Faculdade de Ciências Humanas e Sociais da Universidade do Algarve. Investigadora no CEIS20/Universidade de Coimbra. E-mail: cvilhena@ualg.pt 


\begin{abstract}
This text has as its object discourse analysis on children and juvenile delinquents that circulated in Portugal in the period between the 70 and 90 of the twentieth century. From an empirical point of view, we refer the legislation produced on this subject, as well as the magazine's study "Childhood and Youth", owned by the National Federation of Institutions Protection of Children, within the prescribed time span. We will begin by presenting the historical context of the evolution of the juvenile justice system in Portugal over nine hundred, and then analyze the process of social construction of the child category and young offenders, with particular reference both to those who were considered the causes of this problem, either the proposed solutions.
\end{abstract}

Keywords: Risk; Children and youth; Delinquency; History, Marginality 


\section{Introdução}

A problemática da delinquência na infância/juventude constitui matéria tratada com interesse por inúmeros especialistas e saberes nas últimas décadas. Alvo de debates públicos desde finais do século XIX, a temática dos comportamentos desviantes e da delinquência esteve na origem de diversos estudos ao longo do século XX, no sentido quer de perceber as suas causas, quer a melhor forma de os solucionar. São exemplo deste interesse os estudos sociológicos que surgem nas décadas de 20 e 30 nos EUA, numa tentativa de compreensão do fenómeno da delinquência infantil e juvenil ${ }^{1}$ ou, mais atualmente, os trabalhos oriundos da psicologia que analisam a relação entre estratégias educativas e delinquência ${ }^{2}$. Paralelamente, assiste-se a um interesse crescente por parte dos media em relação a esta questão ${ }^{3}$.

Todo este debate contribuiu para sucessivas reconstruções da categoria criança/jovem delinquente, assim como, em resultado dessas reconstruções, para a emergência de novas formas de intervenção. Em comum temos a ideia de que os crimes cometidos por crianças e jovens devem ser tratados com maior tolerância, uma vez que se considera que estes não podem ser totalmente responsabilizados por esses factos ${ }^{4}$.

1 SHANAHAN, S. Lost and found: The sociological ambivalence toward childhood. Annual Reviews of Sociology, 33, 2007, 407-428.

2 EHIEMUA, S.. Juvenile delinquency: A comparative study between child rearing practices in developed and developing countries. European Journal of Research in Social Sciences, 2(4), 2014, 59-65.

3 CARVALHO, M. J. L. \& FERREIRA, L.. "Infância e risco social: Retratos da imprensa portuguesa”. Sociologia, Problemas e Práticas, 60, 2009, 105-129.

4 FERREIRA, P. M. «Delinquência Juvenil», família e escola. Análise social, Vol. XXXII (143), (4º-5 $), 1997$, pp. 916. 
No que diz respeito à análise sócio-histórica desta problemática, desde o estudo pioneiro de Anthony Platt ${ }^{5}$ vários autores têm analisado a forma como esta categoria particular, a criança delinquente, foi construída e reconstruída, sobretudo durante o século XX, assim como as diferentes soluções propostas, em espaços geográficos e tempos históricos diferentes, para esta questão ${ }^{6}$.

É precisamente a análise da forma como a categoria criança delinquente é construída entre os anos 70 e 90 do século XX, em Portugal, assim como das soluções propostas para a resolução deste problema que constitui o principal objetivo deste trabalho. Para tal recorremos à análise de dois núcleos de informação: 1) a legislação; 2) a imprensa especializada. No que diz respeito ao primeiro núcleo, procedemos à análise dos principais diplomas legais relacionados com a justiça de menores ao longo do século XX, destacando a segunda metade de novecentos. Quisemos compreender as roturas e continuidades na voz do Estado sobre esta matéria. Quanto ao segundo núcleo informativo, serviu de fonte principal para a nossa análise o periódico "Infância e Juventude", na sua segunda série, publicada a partir de 1976, sob a tutela da extinta Direção Geral dos Serviços Tutelares de Menores.

Partimos, assim, de uma das dimensões que, como afirma

5 PLATT, A.. The Child Savers: The Invention of Delinquency. University of Chicago Press, 1969.

6 C.f. GRAFF, H. J.. Remaking growing up: Nineteenth-century America. Social History, XXIV(47), 1991, 35-59.

MARTINS, E. C. A outra educação da infância sem voz expressa na literatura (Séc. XIX - XX). EducareEducere. Ano XIV, Julho, 2010.

DINIZ, A. O ensino dos anormaes - preocupações em Coimbra e em Portugal no início do século XX. Educar em Revista, 23, 2004, 246-253.

ROSE, N. The Psychological Complex: Psychology, Politics and Society in England, 1869-1939. London: Routledge \& Kegan Paul, 1985.

HENDRICK, H. Optimism and Hope versus Anxiety and Narcissism: Some Thoughts on Children's Welfare Yesterday and Today. History of Education, 36(6), 1997,747-768. 
Ferreira (1997) se deve ter em conta para uma compreensão da construção do conceito de delinquência juvenil, ou seja, das "leis, das práticas e das crenças relativas ao comportamento das crianças e dos jovens que governam as instituições responsáveis social e legalmente pelo controlo e tratamento do comportamento considerado delinquente e de outros problemas juvenis"7. Mais concretamente, pretendemos, através de uma análise sócio histórica de um conjunto de discursos sobre esta temática, contribuir para uma melhor compreensão da forma como essas categorias foram sendo construídas e reconstruídas em Portugal, nas últimas três décadas do século XX.

O nosso trabalho ancora-se, do ponto de vista teórico, à História Social da Infância e a autores que têm vindo a trabalhar a temática da delinquência na infância e na juventude ${ }^{8}$. A abordagem metodológica inscreve-se no quadro da análise sócio histórica dado que a interpretação deste fenómeno relacionado com a marginalidade, latus sensu, implica uma visão sistémica e ampla sobre o problema.

7 FERREIRA, P. M. - “ «Delinquência Juvenil», família e escola”. Análise social, Vol. XXXII (143), 1997 (4º -5º, pp. 916.

8 DEKKER, J.H. - "Children at risk in history: a story of expansion”, Paedagogica historica, 45: 1-2, 2009.

DEL CURA GONZALEZ, M. - Medicina y Pedagogía - La Construccion de la Categoria «Infância Anormal» en España (1900-1939), Madrid: Consejo Superior de Investigaciones Cientificas, 2011.

DUARTE-FONSECA, A. C. - Internamento de menores delinquentes - A lei portuguesa e os seus modelos: um século de tensão entre protecção e repressão, educação e punição, Coimbra: Coimbra editora, 2005.

FERREIRA, António Gomes - "Crianças, Alunos e Menores - Elementos para uma compreensão social da infância em Portugal” In PINTASSILGO, Joaquim et al., A História da Educação em Portugal: Balanço e Perspetivas, Porto: Asa, 2006, p. $73-110$.

GODINHO-LIMA, Ana Laura - O Espectro da Irregularidade Ronda o Aluno: um estudo da literatura pedagógica e da legislação sobre a criança-problema. (Tese de Doutorado em Educação). São Paulo, Faculdade de Educação da Universidade de São Paulo, 2004. 
Foi realizada uma análise temática dos textos publicados na revista "Infância e Juventude" que tinham como tema a criança/jovem delinquente. A escolha desta revista prende-se com o facto de ser publicada por uma instituição pública dedicada especificamente aos problemas relacionados com a Infância e Juventude no período temporal previsto.

\section{Modernidade e comportamentos antissociais na encruzilhada do tempo}

Ao longo da modernidade educativa o interesse pela infância foi crescente. Em 1899, Ellen Key ${ }^{9}$ apelidou a centúria que se aproximava como "O Século da Criança" antecipando o lugar central que a infância ocuparia no século XX. Este projeto sociopolítico intensi$\mathrm{vo}^{10} \mathrm{em}$ torno da infância foi aprofundado com o desenvolvimento, ao longo do século XX, de um conjunto de saberes: a medicina, a psicologia ou a pedagogia. Como afirma Rose "a criança moderna tornou-se o foco de inumeráveis projetos que pretendem salvaguardá-la do perigo físico, sexual ou moral, assegurar o seu desenvolvimento "normal", promover ativamente certas capacidades de atributos como a inteligência, a educabilidade e a estabilidade emocional" $"$.

Neste contexto a psicologia desempenha, como demonstrou Nikolas Rose ${ }^{12}$, um papel essencial. Ao conceber traços de normalidade e, consequentemente, permitir identificar aqueles que não se enquadravam na regularidade social, psicológica ou médica proposta na época, os peritos $p s i$, aqueles que elegeram como objeto de estudo

\footnotetext{
9 Esta expressão ficou conhecida pela visão sobre a criança que Ellen Key antecipou.

10 GIDDENS, A. Consequências da modernidade, Oeiras: celta, 1998.

11 ROSE, Nikolas. Governing the soul - the shaping of the private self. Londres: Routledge, 1990, pp. 121.

12 Idem.
} 
e intervenção o comportamento, contribuíram para a emergência de novas categorias de crianças, e uma nova classificação de alguns comportamentos infantis, aquela infância que não se enquadrava nos parâmetros definidos, ou seja, a «infância anormal»» ${ }^{13}$. Contudo, esta não é uma categoria homogénea, como nos explica J. Dekker ${ }^{14}$. Para este autor são diversos os tipos de infância desajustada, emergentes na modernidade, e essas novas categorias foram acompanhadas por diferentes respostas da sociedade e/ou do Estado através do aparecimento de instituições especializadas, destinadas a públicos específicos:

"É a história dos órfãos e orfanatos, de crianças portadoras de deficiência física, como surdez e cegueira, e de casas de aprendizagem com métodos desenvolvidos especificamente para si, de crianças criminosas e casas de reforma, de crianças carentes e casas de resgate, de crianças nervosas e centros psicológicos e psiquiátricos, de crianças com problemas de personalidade e de centros de diagnóstico e terapêuticos, crianças em situação de risco de maus-tratos e abuso sexual, crianças com traumas de guerra, crianças migrantes e os seus riscos específicos, as crianças com distúrbios alimentares, emocionais ou comportamentais, (...) e, finalmente de crianças altamente talentosas" ${ }^{15}$.

Um dos exemplos que maior objetividade pode trazer ao nosso discurso tem a ver com a Infância/juventude com comportamentos antissociais, nomeadamente os jovens delinquentes. Numa tentativa de definição do conceito de delinquência, Pedro Moura Ferreira defende o seguinte:

13 Del Cura Gonzalez, M. - Medicina y Pedagogía - La Construccion de la Categoria «Infância Anormal» en España (1900-1939), Madrid: Consejo Superior de Investigaciones Cientificas, 2011.

14 DEKKER, Jeroen J.H. - "Children at risk in history: a story of expansion". Paedagogica historica, 45: 1-2, 2009.

15 Idem, pp. 18. 


\begin{abstract}
"Num sentido amplo, a delinquência refere todo o tipo de infracção criminal que ocorrer durante a infância e a adolescência. Num sentido mais restrito, a delinquência envolve o conjunto de respostas e de intervenções institucionais e legais em relação a menores que comentem infracções criminais ou que se encontram em situações ou exibem comportamentos potencialmente delinquentes, nomeadamente nos casos em que existe grave negligência familiar ou em que as crianças ou adolescentes revelam comportamentos desviantes e desajustados da realidade psicossocial do grupo etário a que pertencem"16.
\end{abstract}

A delinquência encontra-se associada a comportamentos desviantes da norma instituída, cujas causas podem ser diversificadas, com origem no ambiente social e familiar ou em questões de natureza biológica ou psicológica. P. M. Ferreira defende que as explicações para o fenómeno da delinquência "podem ser agrupadas em torno de duas imagens: a do delinquente subsocializado e a do delinquente socializado" 17 .

No que diz respeito à primeira imagem, esta tem subjacentes as teorias que sublinham a importância do controlo social como solução para o problema, designadamente o controlo por parte da família, que é representada quer como causa, [onde] é incapaz de exercer esse controlo, quer atuando com um carácter preventivo, quando realiza de uma forma eficaz, a supervisão do comportamento das crianças e dos adolescentes.

Relativamente à segunda imagem, o fenómeno da delinquência infantil e juvenil é explicado com base num processo de aprendizagem por imitação, ou seja, defende-se que é a exposição a este tipo de comportamentos, assim como o seu reforço positivo, que levam a criança e o jovem a delinquir. Neste modelo é também enfatizado o papel das estratégias educativas dos pais na promoção, ou não, de comportamentos desviantes.

16 FERREIRA, P. M. “«Delinquência Juvenil», família e escola”. Análise social, Vol. XXXII (143), 1997 (4º-5), pp. 916.

17 Idem, pp. 918. 
Ao longo do século XX, os delinquentes constituíram uma preocupação com expressão legal. Na verdade, a instabilidade destes jovens, com comportamentos e práticas socialmente desajustadas, pressionou os Estados a encontrarem soluções para resolver aquilo que poderia comprometer todo um projeto social e político de progresso.

Ao longo da centúria de novecentos a resposta encontrada por diferentes países europeus, na tentativa de exercer controlo sobre estes jovens e proceder à sua regeneração/recuperação, foi a de legislar e, consequentemente, criar sistemas de justiça de menores. As políticas dirigidas aos delinquentes, pelos diferentes sistemas de justiça, e de acordo com as suas épocas de aplicação, situaram-se entre a defesa de políticas de natureza punitiva/repressiva e/ou políticas voltadas para a proteção, assistência e educação dos menores "desajustados" ou em vias de se tornarem perigosos. António Gomes Ferreira afirma, por exemplo, que em Portugal na década de 30 do século passado:

\begin{abstract}
"As crianças delinquentes ou com manifestos comportamentos anti-sociais eram vistas, pela ideologia positivista da altura, por um lado, como resultado de circunstâncias funestas que afectavam os seus órgãos, que, por sua vez, determinavam atrofias e alterações físicas e patológicas, por outro, como emergentes da hereditariedade que transmitindo "qualidades patológicas" possibilitavam o desenvolvimento de "estigmas de degenerescência"18.
\end{abstract}

Para esse "estádio de perigosidade" contribuíam, de acordo com a retórica discursiva predominante na primeira metade de novecentos, diversos fatores. Entre eles, contavam-se o meio social, familiar e as questões de natureza genética, elementos considerados possíveis potenciadores da delinquência quando não existisse a neces-

${ }_{18}$ FERREIRA, A. G. - "Compreensão do comportamento anti-social no pensamento psicopedagógico moderno". In Gaspar et al (Orgs) - Problemas emocionais e comportamento anti-social, Coimbra: Centro de Psicopedagogia da Universidade de Coimbra, 2001, pp. 55. 
sária harmonia capaz de formar cidadãos plenos, estáveis e úteis para a sociedade. A construção de bons cidadãos dependeria da influência dos diferentes contextos onde os sujeitos mais jovens circulavam.

$\mathrm{Na}$ segunda metade de novecentos, a infância e juventude passou a incorporar um conjunto de influências com origem na cultura norte-americana que chegava a Portugal através do desenvolvimento de diversos meios de comunicação. Nesse período, o menor deixava de ser considerado o infrator, em si mesmo, deslocalizando-se a origem dos problemas do menor, enquanto individuo com culpa, para os fatores socioculturais e para os contextos sociofamiliares. Neste contexto, assiste-se a um processo de valorização da dimensão educativa em relação à retórica da institucionalização oferecida, grosso modo, na primeira metade do século. A educação constituiria um dos principais argumentos "em defesa da sociedade" e no combate à irregularidade e exclusão social na segunda metade de novecentos. Esta mudança que acabamos de referir também pode ser verificada no discurso do Estado ao longo de toda a centúria de novecentos. Para melhor caraterizarmos este processo pareceu-nos relevante retratar, ainda que sumariamente, os principais marcos legais relacionados, principalmente, com a infância e juventude considerada perigosa e/ ou em perigo moral a braços com a justiça ${ }^{19}$.

\section{A delinquência em Portugal no século XX: o discurso do Estado}

No decorrer da modernidade o Estado-Nação consolidou-se através de diferentes mecanismos de natureza monopolizadora ${ }^{20}$.

19 HENRIQUES, H. \& VILHENA, C. A preservação da Infância: Análise de discursos sobre a Criança em perigo moral (Portugal, 1910-1916). Educação em Revista. Belo Horizonte. v.31, n.02. Abril-Junho 2015. p. 61-81.

20 ELIAS, N., O processo civilizador - formação do Estado e Civilização, Vol. II, Rio de Janeiro: Jorge Zahar editor, 1998. 
A Escola (enquanto representante do Estado) e o governo da família fizeram parte desse processo centrípeto, de normalização social e identificação daqueles que "destoavam" do padrão. Ao Estado, socorrendo-se de especialistas e saberes científicos, coube o papel de enquadrar legal e institucionalmente estes indivíduos. No que respeita aos menores delinquentes, esta preocupação assume expressão na publicação de legislação específica ao longo do século XX.

Em Portugal verificaram-se três momentos com características próprias relacionadas com a justiça de menores e, particularmente, com os aspetos direcionados para a delinquência. $\mathrm{O}$ primeiro momento carateriza-se pela publicação da Lei de Proteção à Infância ${ }^{21}$ (LPI) de 27 de Maio de 1911, no começo da $1^{\text {a }}$ República, e toda a sua influência ao longo das décadas seguintes. De acordo com José António Afonso, a LPI tinha como objetivo principal "resgatar a criança aos meios sociais potencialmente degenerativos e que colocavam em causa a ordem social e a coesão familiar" dado que "só com crianças educadas num regime escolar disciplinado, com uma higiene moral escrupulosa, instruídas no conhecimento das coisas e na prática das leis sociais que formam actividades positivas"22 (Afonso, 2011: 184/185) permitiria a edificação de uma sociedade civilizada e adequada, cumpridora de direitos e deveres sociais, garantindo a construção de um "Homem-novo".

O segundo momento relacionado com o processo de recuperação de menores delinquentes, em Portugal, iniciou-se no Estado Novo. De acordo com Tiago Neves "afigurava-se adequado eliminar do direito de menores concepções punitivas que

21 PORTUGAL. Decreto com força de lei de 27 de maio, criando instituições de protecção às crianças e regulando a respectiva organização. Diário do Governo $\mathrm{n}^{\mathrm{o}}$ 137. Ministério da Justiça, Lisboa, 1911.

22 AFONSO, J. A. "O nascimento de uma instituição educativa republicana. Argumentos científicos e pedagógicos”. História. Revista da FLUP. Porto, Iv série, vol.1. 2011, pp. 184/185. 
ainda subsistissem. Nesse sentido, os mecanismos de protecção, marcados ainda por um caráter negativo e repressivo, deveriam tornar-se positivos e educativos" ${ }^{\prime 23}$.

Alinhados com esta ideia, a par da circulação de novas conceções sobre os direitos da criança no plano internacional, foi publicada a Organização Tutelar de Menores em 1962 24 . Do ponto de vista legal, assumiu-se maior interesse na proteção da criança ao invés do carater repressivo proposto anteriormente e associado ao processo de regeneração de menores delinquentes apresentado.

Tiago Neves salienta que o "comportamento delinquente passa a ser visto como um mero sintoma de inadaptação social" ${ }^{25} \mathrm{e}$, deste modo, "aquilo que assume um carácter decisivo é a observação do menor, da sua personalidade, das suas condições de vida e do seu contexto familiar"26, aquilo a que Duarte-Fonseca apelida como o "primado da observação sobre o menor"27.

As alterações políticas e de regime verificadas a partir de 1974 não promoveram alterações ou alternativa a este entendimento proposto pelo legislador através da OTM de 1962. As preocupações imediatas do novo regime instituído eram de ordem política, económica e social. Como salienta Duarte-Fonseca "no rescaldo da euforia pelo fim de um duradouro regime repressivo, o conceito de

23 NEVES, T. Entre educativo e penitenciário - Etnografia de um centro de internamento de menores delinquentes, Porto: ed. Afrontamento, 2008, PP. 21.

24 Decreto-Lei n ${ }^{\circ} 44287$ e n 44288 de 20 de Abril de 1962. Instituiu a organização Tutelar de Menores (OTM1962).

25 Idem.

26 Ibidem.

${ }^{27}$ DUARTE-FONSECA, A. C. - Internamento de menores delinquentes - A lei portuguesa e os seus modelos: um século de tensão entre protecção e repressão, educação e punição, Coimbra: Coimbra editora, 2005, pp. 254. 
autoridade entrara em crise, confundido com o de autoritarismo"28 o que teve reflexos nos processos educativos e, concretamente, na continuidade das lógicas de proteção ao menor instituídas pelo próprio Estado Novo.

\footnotetext{
"Numa época em que tentava ainda desfazer-se esta confusão, era inconcebível que a orientação de princípios da intervenção relativa a menores, tido como familiar ou socialmente inadaptados, fosse teleologicamente deslocada de um quadro que, apesar de tudo, e a coberto da enganadora sedução dos significantes, se reclamava de proteção, assistência e educação, para qualquer outra ordem de fins coercivamente conotáveis" ${ }^{29}$.
}

De acordo com a ideia apresentada, era necessário aprofundar ainda mais o quadro de proteção ao menor uma vez que este, no entender promovido na época, era apenas o resultado das circunstâncias adversas que o envolvia e, por isso, havia que continuar a aposta na máxima proteção do menor e evitar a sua segregação ou privação de liberdade colocando-os numa instituição como, por exemplo, os Institutos de Reeducação ou até mesmo a Prisão-escola de Leiria.

O terceiro momento que aqui pretendemos realçar aprofunda o modelo da Organização Tutelar de Menores no que se refere à ideia de proteção absoluta proposta anteriormente. A OTM de $1978^{30}$ assumia como elemento central de reforma a capacidade da recuperação social dos inadaptados em contextos não judiciários. Para isso foram substituídos os Centros de Observação anexos aos Tribunais Centrais por Centros de Observação e Ação Social, acentuando-se o caracter protetor e educativo do diploma face aos menores e atribuindo-se maior importância aos lares de semi-internato, de transição e resi-

28 Idem.

29 Ibidem, pp. 295.

30 PORTUGAL. Decreto-Lei n. ${ }^{\circ}$ 314/78, de 27 de Outubro. Reorganização da Organização Tutelar de Menores. 
denciais considerando a prática de internamento a última solução possível e desejável.

É neste contexto que na década de 70 surgem as Comissões de Proteção. A OTM de 1978 potenciou o desenvolvimento de comissões especializadas no acompanhamento de menores: as comissões de proteção de menores que passaram a existir apenas em Lisboa, Porto e Coimbra onde estavam instalados os Centros de Observação e Ação Social. A este propósito Eliana Gersão escreve um interessante texto em 1977/1978 onde critica o tempo de demora na instituição destas comissões. Estas comissões, teoricamente, teriam a missão de lidar com um público infrator com idades inferiores a 12 anos com o objetivo de os retirar das malhas dos tribunais de menores, e a consequente estigmatização social, e aplicar-lhes outro tipo de medidas com vista à sua recuperação social ${ }^{31}$ (Gersão, 1978).

As competências dos tribunais de menores, como se designavam desde a década de 40, eram aplicadas de acordo com as idades dos infratores. Deste modo, a ação do Tribunal de Menores, no caso de indivíduos menores de 12 anos era extensiva apenas quando os pais ou representante legal não aceitassem a intervenção tutelar ou reeducativa de instituições oficiais; ou ainda quando se provasse que os menores tivessem cometido crimes com "discernimento". No caso dos menores entre os 12 e os 16 anos de idade, os Tribunais de Menores podiam decretar medidas tutelares se verificassem que os menores tinham uma "dificuldade séria de adaptação a uma vida social normal, pela sua situação, pelo seu comportamento ou pelas tendências que haja revelado"; que se dedicassem "à mendicidade, vadiagem, prostituição, libertinagem, abuso de bebidas alcoólicas ou uso ilícito de estupefacientes"; e pudessem ser "agentes de algum facto qualificado pela Lei penal como crime ou contravenção" 32 .

31 GERSÃO, E. “Comissões de protecção de menores: uma proposta esquecida?". Infância e Juventude. n 1, Jan- Mar., 1978, p. 7-28.

32 Decreto-Lei no $314 / 78$ de 27 de Outubro. (art.13). 
No mesmo sentido os tribunais de menores, até aos 18 anos de idade, podiam "decretar medidas relativamente a menores que sejam vítimas de maus tratos ou que se encontrem em situação de abandono ou desamparo capazes de pôr em perigo a sua saúde, segurança, educação e moralidade; "decretar medidas relativamente a menores que, tendo atingido os 14 anos, se mostrem gravemente inadaptados à disciplina da família, do trabalho ou do estabelecimento em que se encontrem internados; e, ainda, "apreciar e decidir medidas de protecção de menores contra o exercício abusivo de autoridade na família ou nas instituições a que estejam entregues".

As principais medidas a aplicar, previstas na OTM de 1978, eram as seguintes: admoestação; entrega aos pais, tutor ou pessoa encarregada da sua guarda; imposição de determinadas condutas ou deveres; acompanhamento educativo; colocação em família idónea; colocação em estabelecimento oficial ou particular de educação; colocação em regime de aprendizagem ou de trabalho junto da entidade oficial ou particular; submissão a regime de assistência; colocação em lar de semi-internato; colocação em instituto médico-psicológico e internamento em estabelecimento de reeducação.

A sua aplicação centrava-se mais na proteção da infầncia, na assistência às suas necessidades e nos processos educativos como mecanismos de promoção positiva do jovem valorizando a sua ação em meio natural de vida tentando não quebrar os vínculos que ainda possuía com a sociedade ou a família. A Escola, a família e os processos de aprendizagem assumem nos diferentes contextos um importante pilar para a recuperação social destes indivíduos, no mesmo sentido a compreensão das causas que conduziram o menor a praticar determinada infração foi muito valorizado quer em contextos de institucionalização (justiça), quer noutros contextos (sociais).

A identidade dos menores infratores define-se, portanto, de acordo com as realidades sociais, familiares e institucionais em que se movimentam. $\mathrm{O}$ ajustamento do individuo depende do sucesso 
destes contextos na promoção de um conjunto de valores estruturantes junto dos mesmos de modo a torná-los adaptados/integrados à/na sociedade, ou seja a torná-los cidadãos com direitos e deveres perante si mesmo e o próximo.

Estas medidas caracterizaram o panorama português até ao final do século XX. Em 1999, sob o governo socialista liderado por António Guterres, encontraram-se novos entendimentos que levaram à publicação de nova legislação ${ }^{33}$.

\section{A Delinquência no Portugal Democrático: preocupações, tendências e influências sociopedagógicas}

Na segunda metade do século passado, o processo de globalização trouxe novas influências e modelos de vida que foram apropriados pelas populações locais. Entendemos, seguindo de perto Anthony Giddens ${ }^{34}$, o conceito de globalização como o resultado da "intensificação das relações sociais de escala mundial, relações que ligam localidades distantes de tal maneira que as ocorrências locais são moldadas por acontecimentos que se dão a muitos quilómetros de distância e vice-versa". Este novo processo potenciado pela modernidade, uma vez que em si mesma é globalizante, trouxe a Portugal, com algumas características singulares, novas preocupações e problemas relacionados com o objeto de estudo que estamos a analisar.

Ao longo da investigação realizada, entre meados da década de 70 e meados da década de 90 do século XX, a partir do periódico "Infância e Juventude", destacamos a existência de dois eixos de discussão permanentes:

33 Lei no $166 / 99$ de 14 de Setembro.

34 GIDDENS, A. Consequências da modernidade, Oeiras: celta, 1998, pp. 45. 
1. A identificação de novos problemas potenciadores de delinquência em Portugal;

2. A centralidade dos processos educativos, familiares e de ações de prevenção especializadas na resolução dos problemas.

No que diz respeito ao primeiro ponto, verifica-se uma enorme preocupação com a influência de outras culturas juvenis em Portugal provenientes, nomeadamente, dos Estados Unidos da América, designadamente no que diz respeito ao consumo de drogas, um dos principais eixos discursivos que se evidencia no periódico analisado. Os comportamentos desviantes de crianças e jovens aparecem associados a problemas relacionados, entre outros, com o consumo de drogas, destacando-se a preocupação com a circulação de Marijuana, Haxixe, LSD ou álcool nas faixas etárias mais novas. Considerava-se que estas drogas potenciavam círculos viciosos: físicos, psíquicos e sociais. As alterações metabólicas produzidas pelo consumo de drogas, o consumo de (outro tipo) de drogas para evitar sentimentos de culpa e vergonha ou o consumo de drogas como elemento de pertença a um círculo social (pares) eram tidos como elementos que podiam conduzir a comportamentos desviantes, a infrações, e que colocavam em perigo o individuo e a própria sociedade.

O Centro de Estudos da Profilaxia da Droga, criado em Portugal em 1976, constituiu uma possível solução aos problemas identificados com o "intuito de se dar resposta a um problema que, tendo-se agravado de súbito entre a população portuguesa, em especial a juvenil, vem abalando vivamente a opinião pública" ${ }^{35}$. O Decreto-Lei $n^{\circ} 792 / 76$ realçava a importância de olhar para o problema de um modo sistémico dado que "situações de inadaptação social, de conflito na estrutura familiar, de ócio laboral e de insegurança,

35 GERSÃO, E. “Comissões de protecção de menores: uma proposta esquecida?". Infância e Juventude. nº 1, Jan- Mar., 1978, p. 13. 
entre outras, constituem condições de alto risco para o uso da droga, bem como para outras formas de conduta associais ou anti-sociais".

O estudo sobre a delinquência e as relações com a droga foi potenciado com a criação deste instituto. No caso especifico português, de acordo com Carlos Amaral Dias e Henrique Dias Pedro, a "delinquência pode fazer parte do percurso toxicómano, mas não é o próprio percurso" "36. Este estudo de caso elaborado no Centro de Estudos de Profilaxia da Droga de Coimbra realça que estes indivíduos não deviam ser privados da liberdade, mas antes se deveria pensar na "criação de centros mistos de pós-cura e recuperação" onde os especialistas biopsicossociais deviam fazer um acompanhamento progressivo destes sujeitos, oferecendo-lhes oportunidades para se integrarem gradualmente em meio social e assim promoverem a sua "normalização". Não obstante, a atenção dada a este problema com impacto na opinião pública deveria, segundo Eliana Gersão, ser alargado a outros grupos de menores inadaptados. A jurista dá o exemplo do grupo das "prostitutas" adolescentes, dos pequenos "vadios", "mendigos", "libertinos", "delinquentes" ou dos "simplesmente inadaptados" $"$. A abordagem ao menor inadaptado deveria ser realizada do ponto de vista jurídico, quando se justificasse, mas sempre num contexto interpretativo mais lato, estudando as realidades de origem e movimentação do menor.

É nestes públicos/contextos que se destaca a importância que as Ciências Sociais, Humanas e Comportamentais deveriam assumir de forma a facilitar os processos de recuperação social dos menores e respetiva integração em contexto natural de vida. Simone Rozes salienta a centralidade das Ciências Humanas na análise sobre o problema da delinquência. Defende que aos poucos se alargou o

36 DIAS, C. \& PEDRO, H. D. "Toxicomania e Delinquência - Considerações a propósito de 61 casos”. Infância e Juventude. n 1, Jan- Mar., 1979, p. 15.

37 GERSÃO, E. “Comissões de protecção de menores: uma proposta esquecida?”. Infância e Juventude. nº 1, Jan- Mar., 1978, p. 15. 
âmbito de análise face ao que acontecia anteriormente dado que antes o olhar se encontrava focado no menor enquanto "ser solitário". Este alargamento possibilitou novas interpretações uma vez que a análise sobre o menor delinquente, interpretado como um "ser relacional", deriva de fatores socioculturais tão diversos como: as carências educativas da família e a falta de imagens paternas válidas; a reprodução de condutas do desvio; a estigmatização social; as condições de habitação "deploráveis" ou a rejeição pela escola de crianças provenientes de meios mais desfavoráveis ${ }^{38}$.

Associado a estas ideias também encontramos o movimento de urbanização do país e a migração das zonas rurais para as cidades em busca de novos trabalhos e formas de vida e sustentação socioeconómica. Manuel Louzã Henriques realça que "o lar desfaz-se pela sobreocupação dos pais em busca de meios, a cultura degrada-se e desinsere-se do movimento social, a escola demite-se e permeabiliza-se aos valores da decadência, os tempos de ócio desaguam directamente na rua" 39 .

A necessidade dos pais procurarem adaptar-se a um meio, quantas vezes desconhecido, contribuiu para a existência de "vazios" nos processos relacionais que podiam promover comportamentos socialmente inadequados pelos grupos de jovens. Este processo encontra-se muitas vezes associado a grupos que se constituem - gangs - e que se caraterizavam por condutas duvidosas e princípios próprios diferentes da norma social, resultado do "vazio sociofamiliar".

De acordo com um estudo realizado por Maria Helena Pinto Azevedo, publicado parcialmente em 1981, a partir de dados colhidos no Centro de Observação e Ação Social de Coimbra, chegou-se à

38 ROZES, S. "Programa e métodos de tratamento e de readaptação dos jovens delinquentes que foram identificados". Infância e Juventude. n 2, AbrilJunho., 1977, p. 31.

39 Henriques, M. L. "Delinquência juvenil". Infância e Juventude. n 2, AbrilJunho, 1979, p. 28. 
conclusão que $75,9 \%$ das infrações criminais eram cometidas por sujeitos do sexo masculino que atuavam em grupo. Os motivos que conduziram à ação do tribunal foram: a prática de furto, roubo, fogo posto, ofensas corporais, atos de vandalismo, uso e porte de arma de fogo, danos materiais, danos em animais, tentativa de "estupro" e homicídio involuntário. As restantes situações $(24,1 \%)$ tinham que ver essencialmente com vadiagem, refração ao lar, à escola, inadaptação social, libertinagem, indisciplina à escola e comportamento irregular. Estas últimas situações eram consideradas para-delinquentes. É de realçar que esta análise apresenta dados importantes relacionados com os contextos de proveniência destes menores delinquentes. Assinala-se que:

\begin{abstract}
“as circunstâncias socioeconómicas das famílias de origem de um grupo de rapazes enviados pelo Tribunal de Menores para o Centro de Observação e Acção Social de Coimbra, caracterizavam-se por analfabetismo, ocupações consideradas de menos prestígio social (trabalho rural, de serventia, trabalho manual não-especializado), com péssimas condições habitacionais e do ponto de vista económico por uma situação de extrema pobreza" ${ }^{\prime 4}$.
\end{abstract}

Este é o perfil do menor delinquente em Portugal. Fruto de ambientes nocivos ao desenvolvimento adequado do jovem tornava-se imperativo encontrar soluções para os problemas apresentados anteriormente atendendo às especificidades do caso português. Para alimentar todo este processo há autores que apontam a culpa aos «mass-media». A sua influência junto das "culturas juvenis" podia ser mais um elemento desencadeador de comportamentos desviantes por imitação de comportamentos e estruturas culturais diferentes daquelas que conheciam, como é o caso dos Estados Unidos da América através da sua indústria cinematográfica ou até das bandas

40 AZEVEDO, M. H. P. "Delinquência juvenil - alguns aspectos sociopsicológicos". Infância e Juventude. nº 2, Abril- Junho, 1981, p. 19. 
desenhadas consumidas pelos jovens onde a presença de heróis é uma constante ${ }^{41}$.

O segundo aspeto que evidenciamos da análise realizada prende-se com a necessidade de resolver estes comportamentos antissociais, utilizando para o efeito a escola, a família e a comunidade. A OTM de 1978 acentuou a necessidade de uma intervenção que procurasse construir um sentido de autonomia aos menores de modo a interpretar os seus problemas, eventuais potenciadores da delinquência, com o objetivo de resolvê-los e promover a sua recuperação e integração social. A recorrência do discurso aponta para a prevenção como a principal aposta no processo de evitar práticas delinquentes e a de uma "recuperação relacional" no caso de já ter cometido a infração. Em qualquer um dos casos era necessário o recurso a um conhecimento especializado. Ao longo do periódico encontramos inúmeros textos de especialistas (psicólogos, psiquiatras, juristas, etc...) sobre estas matérias (Ex. "Aspectos neuropsicológicos da agressão"42; "Elementos sobre psicopatologia da deliquência"43; "Contribuições para uma análise psicossocial da delinquência"44; "Algumas reflexões sobre as famílias de jovens delinquentes"45; "Prevenção da delinquência juvenil: o papel da escola (...)" ${ }^{46}$. Des-

41 MONTEIRO, M. B. “Os heróis mágicos do écran violento”. Infância e Juventude. n 2, Abril- Junho, 1985, p. 81-85.

42 Caldas, A. C. “Aspectos neuropsicológicos da agressão”. Infância e Juventude. n 2, Abril- Junho, 1985, p. 11-18.

43 Vieira, A. B. "Elementos sobre psicopatologia da deliquência" ". Infância e Juventude. $n^{\text {o }}$ 2, Abril- Junho, 1985, p. 19-24.

44 Vala, J. "Contribuições para uma análise psicossocial da delinquência" ”. Infância e Juventude. $\mathrm{n}^{\circ}$ 2, Abril- Junho, 1985, p. 53-64.

45 Sampaio, D. "Algumas reflexões sobre as famílias de jovens delinquentes" ". Infância e Juventude. $n^{\circ}$ 2, Abril- Junho, 1985, p. 65-69.

46 Walgrave, L. "Prevenção da delinquência juvenil: o papel da escola (...)"”. Infância e Juventude. $n^{\circ}$ 1, Janeiro- Março, 1982, p. 7-47. 
te modo, as dimensões familiares e escolares, articuladas com um conhecimento especializado sobre estas matérias, deveriam ser a principal aposta no sentido de evitar o desajustamento ou adequar o individuo desajustado.

A família constitui uma instituição primária de socialização. É neste contexto que os menores adquirem hábitos, valores e princípios que, mais tarde, podem reproduzir. A preocupação com a dimensão da família, as condições habitacionais, os rendimentos económicos assume relevância na produção da delinquência. Neste sentido, afirmava-se a importância de um lar estruturado: pai e mãe. A associação da delinquência a ambientes familiares desestruturados é evidente. No começo da década de 80 considerava-se que as causas "da situação familiar anormal eram fundamentalmente três: porque um lar normal nunca foi formado (mães solteiras), ou (...) foi desfeito por separação ou abandono dos pais, e orfandade de um ou ambos os pais"

Esta ausência de um contexto familiar harmonioso poderia despertar nos jovens comportamentos pouco adequados. Deste modo, tornava-se relevante que pai e mãe assumissem a sua condição de casal, reproduzindo o que ainda constituía uma marca de uma sociedade profundamente patriarcal, e transmitissem os princípios normalizadores aos seus filhos. Esta seria uma das melhores formas de prevenção sobre a delinquência.

No mesmo sentido, também a Escola surge nos textos analisados como um dos principais instrumentos para prevenir comportamentos inadequados ou para potenciar a recuperação social de menores. De facto, à Escola era reservado um papel central no processo de inclusão social de menores com comportamentos marginais. A este propósito leia-se o testemunho de Hulsman:

47 AZEVEDO, M. H. P. "Delinquência juvenil - alguns aspectos sociopsicológicos". Infância e Juventude. nº 2, Abril- Junho, 1981, p. 26. 
"a escola deve empenhar-se em descobrir e atenuar, na medida do possível, e muito precocemente, os handicaps socio-culturais das crianças ou a manifestação dos seus comportamentos associais. É preciso pois sensibilizar os professores para a sua missão de despistagem sistemática e de redução das inadaptações escolares" ${ }^{\prime 4}$.

A instituição escolar deveria desempenhar um papel de socialização da maior importância em articulação com a família. Porém, em alguns dos discursos encontrados verifica-se que o momento de entrada na Escola constituía, em si mesmo, o "início de uma vida cheia de frustrações e pesados castigos, causa frequente de comportamentos mal-adaptativos" ${ }^{49}$. As frustrações com origem na instituição escolar, uma vez que essa era uma nova realidade que os próprios progenitores muitas vezes desconheciam, constituam motivo de preocupação pois podiam ser promotores de fracasso escolar e conduzir a comportamentos antissociais.

\begin{abstract}
“A escola, ponto de passagem obrigatório, pode influenciar a criança para o bem e para o mal, e não há duvida que algumas são mais férteis que outras em produzir delinquentes (...). Os que não se distinguem intelectualmente pouco contam, são marginalizados, os fracos não são ajudados nas suas incapacidades, os que perturbam são reprimidos por uma autoridade que pouco sabe de crianças e seus problemas, que não faz qualquer esforço para as compreender e ajudar. São pelo contrário, elementos incómodos, que a todo o custo se querem libertar, quando não deles se servem como objecto de escape de uma incontrolada agressividade, o que começa a tornar-se do domínio público «criança de 9 anos espancada pela professora...depois de ter ido ao quadro e não ter conseguido fazer uma conta de multiplicar»" $"$.
\end{abstract}

48 HULSMAN, L.H. "Causas e manifestações de tendências recentes na delinquência juvenil - sua influência nas políticas de prevenção, tratamento e reabilitação de menores delinquentes”. Infância e Juventude. n² 2, Abril- Junho, 1977, p. 33.

49 AZEVEDO, M. H. P. "Delinquência juvenil - alguns aspectos sociopsicológicos". Infância e Juventude. nº 2, Abril- Junho, 1981, p. 31.

50 Idem, pp. 42. 
A Escola deveria constituir-se como uma entidade capaz de promover a autonomia do individuo e de proceder à normalização social dos mesmos. Como verificamos, este aspeto encontra-se presente no periódico em análise uma vez que constituía uma enorme preocupação dado que podia tornar-se um elemento condutor de comportamento inadequados. Era necessário sensibilizar os professores e os outros técnicos para este problema que muitas vezes tinha o seu início na escola.

$\mathrm{Na}$ verdade, estamos perante um discurso aparentemente paradoxal. Por um lado, a instituição escolar assume-se como elemento imprescindível de preparação para a vida futura e, consequentemente, um mecanismo de inclusão social; por outro lado, a escola pode constituir a "arena potenciadora do desvio" quando não são levadas em conta algumas especificidades das crianças e jovens, o meio de origem ou as próprias dificuldades de aprendizagem pelos restantes atores educativos. Gradualmente, a escola passa a ser um território de socialização onde já não importa apenas os conhecimentos e os conteúdos mas também a singularidade de cada estudante evitando a multiplicação de comportamentos e atitudes desconformes.

A OTM de 1978 permitiu que a formação escolar pudesse ser realizada em instituições oficiais ou particulares. Deste modo, a Escola foi ao encontro de algumas instituições de Reeducação. Duarte-Fonseca salienta que a formação escolar "é uma das componentes mais importantes da medida tutelar de internamento" Porém, quando os jovens dão entrada neste tipo de estabelecimentos é necessário combater a carga de negatividade que transportam em relação a eventuais más experiências escolares que tiveram anteriormente. Neste sentido tornava-se necessário "combater a «ideia

51 DUARTE-FONSECA, A. "O ensino básico no estabelecimento de reeducação - a escola primária do Instituto Padre António de Oliveira”. Infância e Juventude. $\mathrm{n}^{\circ}$ 4, Out.- Dez., 1987, p. 55. 
de escola» com que o jovem chega ao internato" 52 . Como defende Isilda Janeiro, era necessário que a escola da instituição fosse "uma Escola diferente":

“(...) uma escola onde o corpo docente forme uma equipa aberta a todas as inovações, onde o ensino não surja separado da vida e das preocupações imediatas. Uma escola que perceba o desenvolvimento intelectual e escolar de uma criança saída de uma família que dispõe de um vocabulário de duzentas palavras não é igual ao de uma criança de uma família, em que a linguagem corrente compreende duas mil palavras. Uma escola que saiba que a maior parte dos sucessos escolares não são prova de uma perturbação orgânica do cérebro, mas sim o resultado de factores culturais, psicológicos e afectivos. Uma escola que, em vez de «pregar moral», tente compreender" ${ }^{33}$.

A necessidade de alterar práticas no interior da escola é uma evidência no excerto anterior. Para a autora, era necessário avaliar não apenas a criança/jovem mas compreender aquilo que a/o circundava e até que ponto influenciava os seus resultados comportamentais, escolares, sociais.

As duas dimensões que identificamos revelaram-se essenciais para a compreensão da retórica predominante nas últimas décadas do século XX. A ideia de proteção, assistência e educação ao menor em perigo materializou-se, em grande parte, num conjunto alargado de discursos científicos sobre a Família, a Escola e o papel do Estado quer na proteção da sociedade face a indivíduos delinquentes, quer na normalização desses sujeitos por via das medidas aplicadas pelo Tribunais de Menores e pelo conhecimento produzido pelas diferentes instituições dependente do Estado como os Centro de Observação e Ação Social introduzidos, com outra roupagem, pela OTM de 1978.

52 Idem.

53 JANEIRO, I. “A escola na instituição - que escola?". Infầncia e Juventude. $\mathrm{n}^{\mathrm{0}}$ 4, Out.- Dez., 1987, p. 63. 


\section{Considerações finais}

Estado, Família e Escola constituem elementos fundamentais à compreensão dos processos de construção social da infância delinquente em Portugal. No mesmo sentido, os processos de normalização ou recuperação social destes menores encontra-se muito dependente dos elementos referidos em articulação com saberes especializados e instituições criadas para o efeito.

Quando analisamos a segunda metade de novecentos percebemos que as instituições Familiar e Escolar continuam a ser centrais na retórica discursiva sobre o processo de normalização social dos jovens. Quer do ponto de vista legal, quer do ponto de vista científico, os discursos confluem no sentido da normalização da delinquência através destes espaços de socialização. Há, portanto, uma lógica de continuidade discursiva que atravessa da primeira para a segunda metade de novecentos. Não nos surpreende, dada a influência permanente de instituições, como a Igreja e o Estado, que promoveram uma ideia de família (patriarcal) ou uma determinada ideia de Escola nesta centúria.

Porém, se esta pode ser uma importante marca de continuidade, há outros aspetos que divergem. As formas de regeneração/ recuperação social são diferentes. Na segunda metade de novecentos insiste-se, independentemente do regime político vigente, na necessidade de proteção ao menor que se faria, invariavelmente, por via da escola, de uma família normal ou de instituições especializadas através de uma lógica preventiva. Por outro lado, surgiram novas preocupações decorrentes do processo moderno de globalização. A influência de outras realidades nacionais, por exemplo através dos meios de comunicação, constituía elemento de preocupação que podia potenciar a delinquência em Portugal. A família assumia aqui um papel relevante de modo a constituir-se como o primeiro filtro em relação a determinadas mensagens transmitidas pelos "mass-media". 
Também se pode considerar retórica discursiva predominante a ideia de autonomia do individuo. Essa autonomia, quando já institucionalizado, deveria ser promovida através da formação escolar e profissional. A escola quando bem preparada para lidar com este público podia constituir-se como alavanca de integração social. Neste sentido, encontramos inúmeros estudos de psicólogos ou psiquiatras que tendem a constituir-se como processos indicadores de normalização do individuo. Ao contrário da lógica "curativa" da primeira metade de novecentos, associada ao modelo médico, na segunda metade de novecentos investia-se sobretudo nas ciências sociais, humanas e comportamentais, com destaque para o papel da psicologia ${ }^{54}$.

Este discurso encontra-se presente no periódico analisado. Era necessário investir num conhecimento mais amplo que aquele oferecido apenas pela perspetiva clínica. Deste modo, com o florescimento das ciências sociais e humanas isto torna-se particularmente visível. Este novo entendimento possibilitou a emergência de atividades que se foram profissionalizando em torno destas matérias nomeadamente, além dos psicólogos, os especialistas ligados ao trabalho social. Novas ferramentas foram aplicadas nas instituições que o Estado criou, nomeadamente nos Centros de Observação e Ação Social que destacamos neste trabalho, como é o caso de inquéritos de grande abrangência, significa que procuravam já abordar o menor numa perspetiva plural e sistémica.

Todo o processo descrito e analisado neste texto toma a perigosidade do individuo como um desiderato social que depende de fatores sociais, culturais, psicológicos, mas também da ação do Estado e dos especialistas que assumem a defesa do "interesse da sociedade" em vários espaços institucionais em troca da valoriza-

54 POPKEWITZ, T., \& BLOCH, M. Construindo a criança e a família: Registos de administração social e registos de liberdade In A. Nóvoa \& J. Schriewer (Eds.), A difusão mundial da escola, Lisboa: Educa,2000, pp. 33-68. 
ção dos grupos profissionais que representam. Neste caso o bom cidadão seria aquele que fosse capaz de escutar os profissionais à sua volta e colocar em prática os seus conselhos. Este seria, provavelmente, o único caminho de uma integração social bem-sucedida. Entende-se, portanto, que apenas na longa duração podemos discutir objetos de estudo desta natureza. O "fator histórico" assume uma centralidade inegável.

Enviado em 28 de março de 2014

Aprovado em 30 de setembro de 2015 